\title{
Letters
}

\section{Animal research}

SIR

As a simple bone-setter, I find it awkward and difficult to respond to a professor of philosophy of the stature of Timothy Sprigge. ${ }^{1} \mathrm{My}$ intention was simply to illustrate that many people take high-minded positions without adequate contemplation of the consequences. For example, a few years ago homeowners in California voted to rescind their property taxes, and yet reacted with shock and dismay when their (now under-funded) school system did a poorer job. Abhorring animal research is a perfectly reasonable position, but prohibiting that research may lead to fewer medical advances. Thus, such a position does not come cheaply.

The professor's cavil that painless and painful research should be distinguished may be valid; yet it could easily be satisfied on a form, such as mine, that allows selective invocation of the various clauses. His analogy to the autobahn is less to the point, I feel, as it fails to differentiate between those things which are made for a bad purpose (roads for war) versus those that are made by a bad means ("unethical" research).

Many who jump on the bandwagons of protest movements have not fully explored the consequences that may result from their positions. That such a phenomenon is not rare does not render calling attention to it futile or wrong.

\section{Reference}

1 Sprigge T. A reply to Joseph Bernstein. Fournal of Medical Ethics 1996; 22: 302-3.

\section{JOSEPH BERNSTEIN MD \\ University of Pennsylvania, Pennsylvania, USA}

\section{QALYs, lotteries and veils}

SIR

In Dr Hope's editorial discussion of the just allocation of scarce health resources $^{1}$ he uses a simplified model in which Michelle and Nina are possible recipients of a heart transplant. There is only one available and the one who doesn't get it will soon die. The element missing in the discussion is the patients' contribution to the decision-making.

If they are both incompetent then all the ensuing debate - Harris, Kuhse, Mckie, Richardson and Singer are referred to as participants remains relevant and the development of useful guidelines urgently necessary. But first Michelle and Nina, who are not described as incompetent, should be given the facts and asked their views on the matter.

One of them may be a Jehovah's Witness or have other reasons, independent of scriptural authority, for being unwilling to accept a replacement heart. Even if the reason seemed poor to the surgeon the refusal would still have to be accepted.

If both potential recipients are willing in principle to accept the proffered treatment they might still contribute to the decision-making. One might feel that most of her life-plans have now been fulfilled and that she is viewing her coming death in a spirit of tranquil acceptance. For that reason, or one of many others, she might recognise the other's claim as greater than her own. Acts of heroism and self-sacrifice seem to be out of fashion nowadays but they have happened and been regarded as acceptable, indeed admirable, behaviour throughout recorded history.

Involving the patients in the decision-making will certainly not by itself solve the just allocation problem but it may contribute to a solution. Whether it does or not, casting the patient at the outset in the rôle of passive recipient (or non-recipient) of possible treatment is not an acceptable starting point.

\section{Reference}

1 Hope T. QALYs, lotteries and veils: the story so far. Fournal of Medical Ethics 1996; 22: 195-6.

JEAN DAVIES 56 Marlborough Road, Oxford OX1 $4 L R$ 